\section{Inherited platelet diseases with normal platelet count: phenotypes, genotypes and diagnostic strategy}

\author{
Paquita Nurden, ${ }^{1}$ Simon Stritt, ${ }^{2}$ Remi Favier ${ }^{3}$ and Alan T. Nurden ${ }^{1}$

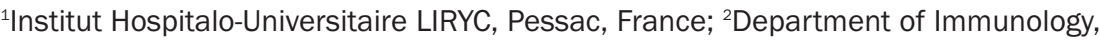 \\ Genetics and Pathology, Uppsala University, Uppsala, Sweden and ${ }^{3}$ French National \\ Reference Center for Inherited Platelet Disorders, Armand Trousseau Hospital, \\ Assistance Publique-Hôpitaux de Paris, Paris, France
}

\section{ABSTRACT}

$\tau$ nherited platelet disorders resulting from platelet function defects and a normal platelet count cause a moderate or severe bleeding diathesis. Since the description of Glanzmann thrombasthenia resulting from defects of ITGA2B and ITGB3, new inherited platelet disorders have been discovered, facilitated by the use of high throughput sequencing and genomic analyses. Defects of RASGRP2 and FERMT3 responsible for severe bleeding syndromes and integrin activation have illustrated the critical role of signaling molecules. Important are mutations of P2RY12 encoding the major ADP receptor causal for an inherited platelet disorder with inheritance characteristics that depend on the variant identified. Interestingly, variants of GP6 encoding the major subunit of the collagen receptor GPVI/FcR $\gamma$ associate only with mild bleeding. The numbers of genes involved in dense granule defects including Hermansky-Pudlak and Chediak Higashi syndromes continue to progress and are updated. The ANO6 gene encoding a $\mathrm{Ca}^{2+}$-activated ion channel required for phospholipid scrambling is responsible for the rare Scott syndrome and decreased procoagulant activity. A novel EPHB2 defect in a familial bleeding syndrome demonstrates a role for this tyrosine kinase receptor independent of the classical model of its interaction with ephrins. Such advances highlight the large diversity of variants affecting platelet function but not their production, despite the difficulties in establishing a clear phenotype when few families are affected. They have provided insights into essential pathways of platelet function and have been at the origin of new and improved therapies for ischemic disease. Nevertheless, many patients remain without a diagnosis and requiring new strategies that are now discussed.

\section{Introduction}

In this review we compare clinical, biological and genetic characteristics of inherited platelet disorders (IPD) with abnormal platelet function but a normal platelet count (listed in Table 1) and highlight anti-ischemic drugs developed based on the discoveries made regarding these disorders. ${ }^{1-10}$ A low platelet count does not exclude altered platelet function but we refrain from repeating details for disorders such as Bernard-Soulier and gray platelet syndromes included in our companion paper in this journal and summarized in Online Supplementary Table S1. ${ }^{11}$ After briefly detailing therapy, we discuss the current lessons and perspectives for clinical practice and highlight how it is important for clinicians to constitute a pivot between genetic platforms and basic research.

\section{Glanzmann thrombasthenia}

With a worldwide distribution, Glanzmann thrombasthenia (GT) is the most common platelet function disorder. ${ }^{12}$ Most importantly, studies on it led to the characterization of the $\alpha \operatorname{IIb} \beta 3$ integrin mediator of platelet aggregation (Figure 1);
Ferrata Storti Foundation
Haematologica 2021
Volume 106(2):337-350

\section{Correspondence: \\ PAQUITA NURDEN \\ paquita.nurden@gmail.com}

Received: June 13, 2020.

Accepted: August 12, 2020.

Pre-published: November 5, 2020.

https://doi.org/10.3324/haematol.2020.248153

(C)2021 Ferrata Storti Foundation

Material published in Haematologica is covered by copyright. All rights are reserved to the Ferrata Storti Foundation. Use of published material is allowed under the following terms and conditions:

https://creativecommons.org/licenses/by-nc/4.0/legalcode. Copies of published material are allowed for personal or internal use. Sharing published material for non-commercial purposes is subject to the following conditions: https://creativecommons. org//icenses/by-nc/4.0/legalcode, sect. 3. Reproducing and sharing published material for commercial purposes is not allowed without permission in writing from the publisher. 
Table 1. Principal named inherited platelet function disorders with a normal platelet count

\begin{tabular}{|c|c|c|c|c|c|c|}
\hline $\begin{array}{l}\text { Disease } \\
\text { - name } \\
\text { - OMIM }\end{array}$ & $\begin{array}{l}\text { Gene } \\
\text { - transmission } \\
\text { - protein }\end{array}$ & $\begin{array}{l}\text { Platelets } \\
\text { - count } \\
\text { - volume } \\
\text { - granules }\end{array}$ & $\begin{array}{l}\text { Isolated or } \\
\text { syndromic } \\
\text { - bleeding } \\
\text { severity }\end{array}$ & $\begin{array}{l}\text { Principal platelet } \\
\text { function defects }\end{array}$ & Biology & Ref \\
\hline $\begin{array}{l}\text { Glanzmann } \\
\text { thrombasthenia } \\
273800\end{array}$ & $\begin{array}{l}\text { ITGA2B/ITGB3 } \\
\text { AR (biallelic) } \\
\alpha \text { Ilb } \beta 3 \text { integrin }\end{array}$ & $\mathrm{N} / \mathrm{N} / \mathrm{N}$ & $\begin{array}{l}\text { Isolated } \\
\text { Major bleeding }\end{array}$ & $\begin{array}{l}\text { Absence of platelet aggregation } \\
\text { with all agonists. Positive response } \\
\text { to ristocetin } \\
\text { Clot retraction often defective }\end{array}$ & $\begin{array}{l}\text { Defects of the } \alpha \text { IIb } \beta 3 \text { integrin: } \\
\text { Type 1: }<5 \% \\
\text { Type } 2: 5 \%-20 \% \\
\text { Variant: }>20 \% \text { but non functional } \\
\text { No binding of Fg }\end{array}$ & $12-22$ \\
\hline $\begin{array}{l}\text { RASGRP2- } \\
\text { (CalDAG-GEFI)- } \\
\text { RD } \\
615888\end{array}$ & $\begin{array}{l}\text { RASGRP2 } \\
\text { AR (biallelic) } \\
\text { CalDAG-GEFI }\end{array}$ & N/N/N & $\begin{array}{l}\text { Isolated } \\
\text { Major bleeding } \\
\text { syndrome }\end{array}$ & $\begin{array}{l}\text { Reduced or absent aggregation } \\
\text { Positive response to ristocetin } \\
\text { Normal response with PMA }\end{array}$ & $\begin{array}{l}\text { Normal presence but defective } \\
\text { activation of } \alpha \operatorname{IIb} \beta 3 \text {. }\end{array}$ & $25-28$ \\
\hline $\begin{array}{l}\text { Leukocyte } \\
\text { adhesion } \\
\text { deficiency-III }\end{array}$ & $\begin{array}{l}\text { FERMT3 } \\
\text { AR (biallelic) } \\
\text { Kindlin-3 }\end{array}$ & $\begin{array}{l}\mathrm{N} / \mathrm{N} / \mathrm{N} \\
\text { Leukocytosis }\end{array}$ & $\begin{array}{l}\text { Syndromic with } \\
\text { severe infections } \\
\text { Osteopetrosis }\end{array}$ & $\begin{array}{l}\text { Absence of platelet aggregation with } \\
\text { all agonists } \\
\text { Positive response to ristocetin. }\end{array}$ & $\begin{array}{l}\text { Normal presence of } \alpha \operatorname{llb} \beta 3 \text {. } \\
\text { Defect of } \beta 1, \beta 2 \text { and } \beta 3 \text { activation }\end{array}$ & $29-34$ \\
\hline
\end{tabular}

(LAD-III syndrome)

612840

Scott syndrome $\quad$ ANO6 (TREM16F) N/N/N

262890

EPHB2-RD

618462

AR (biallelic)

Anoctamin-6

EPHB2

P2Y12 receptor-RD P2RY12

609821

$\mathrm{AD}$

AR (biallelic)

EPHB2

$\mathrm{N} /$ some
elongated
platelets/N

(inconstant)

Major bleeding

Isolated Defective platelet-derived thrombin

Bleeding after surgery

Isolated

Spontaneous

bleeding and

after lesions

AR (biallelic)

P2Y12

$\mathrm{N} / \mathrm{N} / \mathrm{N}$

Isolated

Bleeding can be

severe. For $\mathrm{AD}$

disease bleeding

frequently mild

GPVI-RD

GP6

AR (biallelic)

$\mathrm{N} / \mathrm{N} / \mathrm{N}$

GPVI

Isolated

614201

(BPXAR

TBXA2 receptor-
RD 614009

TBXA2R
$\mathrm{AD}$
$\mathrm{TP} \alpha$

Hermansky-

AR (biallelic)

Pudlak syndrome

10 Genes accor

(HPS): 10 subtypes subtypes

OMIM:

HPS1,3,4,5,6

HPS1:203300

HPS2:608233

HPS3: 614072

HPS4: 614073

HPS5: 614074

HPS6: 614075

HPS7: 614076

HPS8: 614077

HPS9: 614171

HPS10: 617050

\section{Chediak-Higashi}

syndrome (CHS)

214500

encoded for

HPS1,3,4,5,6

HPS2 for AP3B1

HPS7 for Dysbindin

HPS8 for BLOS3

HPS9 for Pallidin

HPS10 for AP3D1

\section{$\mathrm{N} / \mathrm{N} / \mathrm{N}$}

or mild.

Positive response to ristocetin

Defective white cell functions

\section{formation}

Defect of microvesiculation

Defective platelet response to

collagen, ADP, AA and TXA analogs

ADP reversible aggregation even at

high doses. Response reduced

with collagen, AA; reversible. with TRAP.

Defective VASP de-phosphorylation

after ADP stimulation

Absence of response with collagen,

Cvx or CRP.

Decreased binding of fibrin and

other ligands

Absence of response to AA

Isolated

Post-surgery

and TXA analogs.

bleeding

\section{N/N/defect of}

Syndromic

OCA HPS1-10

granules

-Pulmonary fibrosis and granulomatous colitis, HPS1,4

-Immunodeficiency and neutropenia,

HPS2, 10

-Mild or severe

bleeding syndrome

HPS1-10

\section{Defect of aggregation to ADP,} collagen, AA

\section{Defect of secretion}

whatever the agonist used

Decreased or absence of

dense granules

Defect of CD63

Defect of $\beta 1, \beta 2$ and $\beta 3$ activation

Lack of $\mathrm{Ca}^{2+}$-dependent translocation $\quad 35-42$ of PS to the surface of platelets and red cells

Tyrosine phosphorylation of intermediates 43 involved in GPVI and G-protein-coupled receptor mediating signaling

Defect of Gia-coupled P2Y12 receptor linked to adenylate cyclase and

PI3-kinase activation

ack or nonfunctioning of GPVI in complex with FCR $\gamma$. Impaired signaling through a pathway involving PLC $\gamma 2$

Defective TP $\alpha$-coupled signaling via Gq-protein; signaling pathway involves PLC $\beta$

Platelet storage pool disease affecting $\quad 67-73$ dense granules member of the lysosomal-related organelle family. Gene defects manifested via altered function of BLOC1-3 and AP-3 complexes during organelle biogenesis

\begin{tabular}{|c|c|}
\hline 214500 & LYST \\
\hline $\begin{array}{l}\text { Cytosolic } \\
\text { phospholipase } \\
\text { A2- syndrome } \\
600522\end{array}$ & $\begin{array}{l}\text { PLA2G4A } \\
\text { AR (biallelic) } \\
\text { cPLA2 }\end{array}$ \\
\hline
\end{tabular}

N/N/defect of Mild bleeding dense granules

Multi-syndromic

OCA, recurrent infections, immune dysregulation with lymphoproliferative histiocytosis

Isolated

Moderate bleeding

Recurrent GI ulceration
Defect of aggregation to ADP, collagen, AA

Defect of secretion whatever

the agonist

Decrease or absence of dense

granules

Defect of platelet response to $\mathrm{AA}$

collagen, and absence of second

wave with $\mathrm{ADP}$
Lysosomal storage disorder affecting platelet dense $(\delta)$ granules, member of the lysosomal-related organelle family. LYST is a member of the BEACH protein family

Signaling pathway defect

Impaired liberation of AA from

membrane phospholipids 


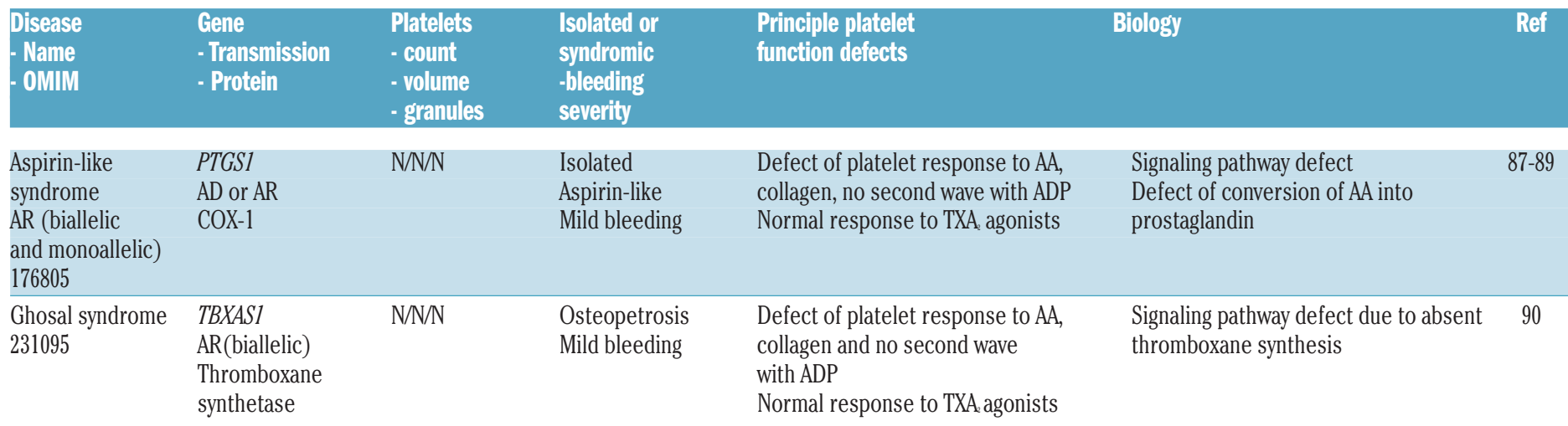

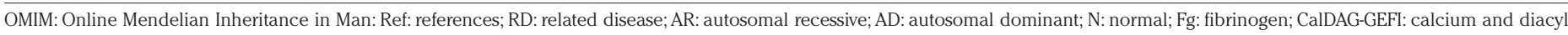

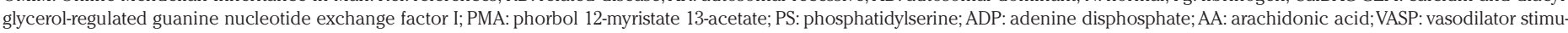

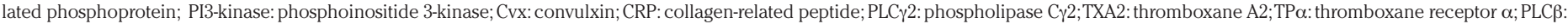
phospholipase C $\beta$; OCA: oculocutaneous albinism; BLOC1-3: biogenesis of lysosome-related organelles complex 1-3; GI: gastrointestinal; PLA2: phospholipase-A2; Cox-1: cyclooxygenase-1

this was accompanied by the emergence of a new category of powerful anti-ischemic drugs. ${ }^{13,14}$

\section{Definition}

Classically, GT is a severe bleeding diathesis with autosomal recessive transmission caused by an absence of platelet aggregation induced by all physiologic agonists.

\section{Clinical phenotype}

The clinical phenotype is marked by life-long spontaneous easy bruising, epistaxis and gum bleeding, often requiring platelet transfusions. Gastro-intestinal hemorrhage, menorrhagia and severe bleeding at menarche feature prominently, as does trauma-related hemorrhage. The first signs usually appear at birth, are intense during childhood but tend to decrease in later life. GT is prevalent in ethnic communities. ${ }^{15}$

\section{Biological phenotype}

Patients have a normal platelet count and morphology. Most have platelets lacking $\alpha I I b \beta 3$ although some express residual amounts but insufficient to support platelet aggregation: these have been termed type I and type II thrombasthenia. ${ }^{12} \mathrm{~A}$ third category consists of phenotypic variants in which platelets have reduced to normal amounts of $\alpha I I b \beta 3$ unable to function. While type I GT patients possess platelets that fail to promote clot retraction, this can be subnormal or normal for some with residual or variant $\alpha \operatorname{IIb} \beta 3$. Platelets respond to ristocetin and adhere to subendothelial matrix components under flow yet fail to spread; intriguingly they can attach to fibrin. If bleeding first occurs late in life, care must be taken to exclude acquired GT, which often has an immune origin. ${ }^{16}$ The severity of bleeding in GT is independent of the subtype.

\section{Genotype}

Several hundred GT patients and their families have undergone gene sequencing. ${ }^{12,17,18}$ Mutations extend across both ITGA2B and ITGB3 and include missense mutations, stop codons, small deletions, inserts or duplications, splice defects often with frame-shifts. In classic GT, defects prevent or greatly limit the passage of the affected subunit (and the pro- $\alpha I I b \beta 3$ precursor) across the endoplasmic reticulum and the Golgi apparatus. The absence or incorrect conformation of one subunit results in the destruction of both the mutated and the unused normal subunit in maturing megakaryocytes. An exception is the ability of $\beta 3$ to complex with av, forming av $\beta 3$, which is present in small amounts in platelets but is a major integrin of endothelial and other cells. For both ITGA2B and ITGB3 defects the bleeding phenotype predominates and the absence of av $\beta 3$ does not lead to major additive defects. Large gene deletions are rare. ${ }^{17}$ Recent haplotype analysis suggests that the mutational landscape of GT is constantly renewing. ${ }^{19}$

Missense mutations in domains such as the terminal $\beta$ propeller of $\alpha$ IIb and in the $\beta \mathrm{I}$ (or $\beta \mathrm{A}$ ) region of $\beta 3$ have helped to identify interfaces where $\alpha I I b$ and $\beta 3$ are in contact (Figure 1). ${ }^{19}$ Rare non-synonymous missense substitutions such as the classic p.D145N/Y and p.R240O/W substitutions permit $\alpha \operatorname{IIb} \beta 3$ expression and give rise to variant GT in which the integrin fails to function (Figure 1). These have been vital to the identification of key residues within the metal ion-dependent adhesion site (MIDAS) and adjacent domains of $\beta 3$ that are essential for $\mathrm{Ca}^{2+}$ and ligand binding. ${ }^{12,13,18}$ Variant GT can also involve intracellular domains abrogating "inside-out" signaling linked to integrin activation; these include the p.S778P and p.R750ter mutations in $\beta 3 .{ }^{18}$ Resting $\alpha I I b \beta 3$ has a bent configuration; on platelet activation; conformational changes emanating from the cytoplasmic domains promote exposure of the ligand-binding epitopes and lead to its extension. ${ }^{20,21}$ Fibrinogen is the principal ligand for aggregation although other adhesive proteins can participate. Occupied $\alpha \operatorname{IIb} \beta 3$ undergoes further conformational changes, including clustering, providing "outside-in" signaling pathways essential for thrombus consolidation, platelet spreading and clot retraction. ${ }^{13}$ Variants within the cytoplasmic domains of $\alpha I I b$ or $\beta 3$ interfere with the binding of talin and kindlin-3 during early $\alpha \operatorname{Ilb} \beta 3$ activation. ${ }^{12}$ Rare gain-of-function monoallelic variants in cytoplasmic and membrane proximal domains promote spontaneous conformational changes that result in macrothrombocytopenia, as detailed in our companion paper. ${ }^{11}$ Significantly, recent data obtained by next-generation sequencing have begun to reveal combinations of variants in different genes that modify the GT phenotype. ${ }^{22}$

\section{Target for anti-platelet therapy}

Because of the importance of $\alpha \operatorname{IIb} \beta 3$ in the formation of arterial thrombi, a generation of antiplatelet drugs block- 
ing $\alpha \operatorname{Ilb} \beta 3$ function was developed some 20 years ago. ${ }^{13}$ The main drugs are abciximab, a humanized Fab fragment of the murine monoclonal antibody 7E3 (C7E3), integrilin, a KGD-based cyclic heptapeptide and tirofiban a synthetic non-peptide inhibitor; all are given intravenously. ${ }^{13,23}$ These inhibitors have basically been used in acute coronary syndromes. While the associated bleeding risk has now restricted their use, they are still recommended for bailout in shunt thrombosis or as a bridge to supplement platelet inhibition by orally taken drugs such as antiP2Y12 inhibitors. ${ }^{24}$

\section{RASGRP2-(CaIDAG-GEFI)-related disease}

In 2014 a missense mutation (p.G248W) in RASGRP2 coding for calcium and diacylglycerol-regulated guanine nucleotide exchange factor I (CalDAG-GEFI) was reported for siblings with a severe bleeding disorder and much reduced platelet aggregation despite normal $\alpha \mathrm{IIb} \beta 3$ levels. ${ }^{25}$ Since this report, a characteristic GT-like defect of platelet function has been confirmed worldwide for 23 cases, as recently reviewed by Canault and Alessi. ${ }^{26}$

\section{Definition}

Gene variants of RASGRP2 represent a new autosomal recessive inherited bleeding disorder linked to major defects of platelet signaling resulting in impaired $\alpha \mathrm{Ilb} \beta 3$ activation (Figure 2). CalDAG-GEFI activates Rap1, which initiates "inside-out" signaling for $\alpha$ Ilb $\beta 3$ promoting the binding of talin to shift the integrin into its high-affinity state. ${ }^{27}$ Both mouse and human platelets lacking functional CalDAG-GEFI undergo a slow but sustained activation that supports the formation of small thrombi at low shear such as those found in the venous system but not the large thrombi characteristic of arterial blood flow.

\section{Clinical phenotype}

Bleeding manifestations start early in life and can be severe. Epistaxis is common and most patients have other cutaneous bleeds. Gastrointestinal bleeding has been reported in four patients and menorrhagia in seven out of nine women. ${ }^{26}$ The bleeding diathesis is not truly syndromic; CalDAG-GEFI is found in other blood cell lineages, vascular cells and the brain striatum and has been implicated in Huntington disease. ${ }^{26}$ It often occurs in ethnic groups. One case, a male of Jamaican origin, successfully underwent surgery for a brain tumor under recombinant activated factor VII administration despite inefficacy of platelet transfusions. ${ }^{28}$

\section{Biological phenotype and genetics}

A critical characteristic is that residual platelet aggregation and elevation of $\mathrm{Ca}^{2+}$ level, which is key for CalDAGGEFI activity, is retained for high doses of some physiological agonists. ${ }^{26}$ Furthermore, $\alpha$ Ilb $\beta 3$ fails to activate normally with decreased binding of the PAC1 IgM monoclonal antibody. Phorbol 12-myristate 13-acetate (PMA) activates Rap1 independently of surface receptors and CalDAG-GEFI and PMA-induced platelet aggregation is a diagnostic test for this disease. Interestingly, platelet spreading on a collagen surface is much decreased and while platelets attach to fibrinogen, lamellipodia are not formed. In the profile of RASGRP2 variants updated by Canault \& Alessi in 2020, ${ }^{26} 12$ of the 23 families had a premature stop codon or frameshift mutations while the others possessed missense mutations in functional domains important for CaLDAG-GEFI activity.
Integrin in bent resting state. On activation it straightens and exposes the epitopes that bind Fg and other ligands allb and $\beta 3$ terminal domains contain residues that assure $\mathrm{Ca} 2+$ and ligand binding including MIDAS, ADMIDAS and p.SyMPS domains on $\beta 3$

Cytoplasmic domains assure the binding of talin and kindlin-3 esential for integrin activation

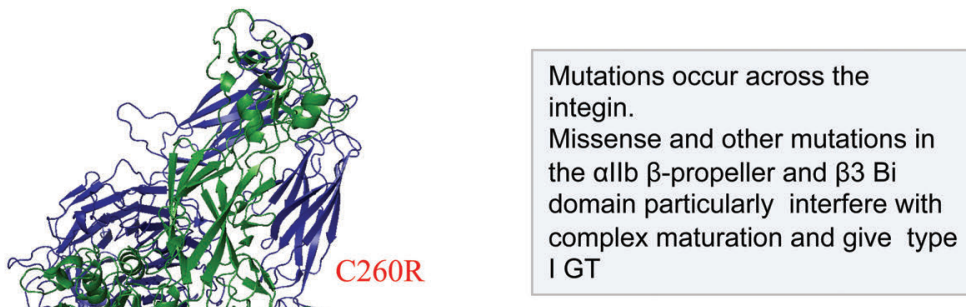

D145Y, R240Q/W mutations in the MIDAS and ADMIDAS give variant forms with severe bleeding. Mutations in the $\beta 3$ disulfide-rich EDF and the cytoplasmic domains can be gain-of function leading to macrothrombocytopenia

Figure 1. Integrin $\alpha$ llb $\beta 3$ and Glanzmann thrombasthenia. The model illustrates the bent resting mature integrin and shows the many interactions between $\alpha$ llb (green) and $\beta 3$ (violet). Much information has been obtained from variant forms (noted in blue) that block functional sites in the extracellular and cytoplasmic domains while allowing $\alpha \mathrm{llb} \beta 3$ expression. Other rare mutations (in red) give rise to activated integrin. Full information on mutations giving rise to Glanzmann thrombasthenia is found in Nurden \& Pillois. ${ }^{18}$ Fg: fibrinogen; GT: Glanzmann thrombasthenia. 


\section{Leukocyte adhesion deficiency III syndrome}

Around 2009, several groups reported that genetic variants of FERMT3 encoding kindlin-3, which is expressed in all hematopoietic cells, caused leukocyte adhesion deficiency III (LAD-III) syndrome. ${ }^{29}$ Kindlin-3 together with its paralogs kindlin-1 and kindlin-2 are key regulators of cellular functions and cell-matrix interactions but kindlin-3 predominates in platelets.

\section{Definition}

LAD-III syndrome, with an autosomal recessive inheritance, combines a rare immunodeficiency and bleeding syndrome of extreme severity characterized by leukocytosis, platelet dysfunction and recurrent infections. The genetic defects result in loss of activation of $\beta 1, \beta 2$ and $\beta 3$ integrins.

\section{Clinical phenotype}

Patients are detected when children have GT-like bleeding with severe non-purulent infections and often osteopetrosis. The clinical phenotype is based on the description of a limited number of largely homozygous patients mostly from ethnic Turkish and Arab populations. ${ }^{29}$

\section{Biological phenotype and genetics}

As in GT, platelets of patients with LAD-III syndrome fail to aggregate in response to all physiological agonists and PMA. ${ }^{30}$ This translates into markedly reduced thrombus formation when whole blood is perfused over collagen, von Willebrand factor or fibrinogen-containing microspots. ${ }^{31} \alpha \operatorname{Ilb} \beta 3$ integrin is present but fails to bind fibrinogen or the PAC-1 monoclonal antibody when platelets are activated (Figure 2). Most disease-causing variants in FERMT3 abrogate kindlin-3 expression. ${ }^{29}$ As first shown in mice, kindlin-3 is an essential cytoplasmic cofactor for the activation of $\beta 1, \beta 2$ and $\beta 3$ integrins. ${ }^{32}$ Kindlin-3 binds in a phosphorylation-dependent manner to a subterminal NITY motif of the $\beta 3$ cytoplasmic tail; it coordinates with talin, which binds independently to trigger "inside-out" integrin activation. ${ }^{27,32}$ Initially there was controversy about the role of a CaLDAG-GEFI mutation in this disorder but this was dispelled when a splice site mutation in RASGRP2 observed in seven subjects with LAD-III syndrome was shown to be in linkage disequilibrium with FERMT3; the two genes are located very closely on chromosome 11q. ${ }^{33,34}$ Most mutations are nonsense or involve frameshifts.

\section{Defects of $\alpha \mathrm{llb} \beta 3$ activation}

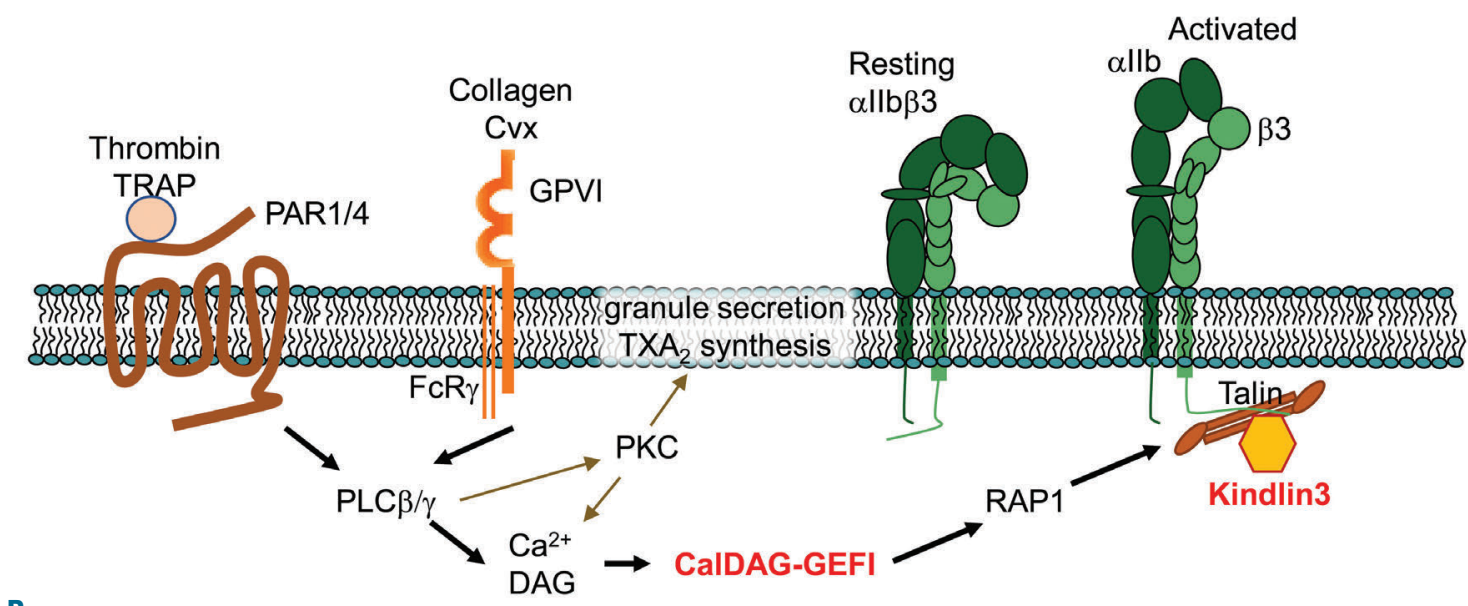

B

\section{RASGRP2-(CaIDAG-GEFI)-RD: Defects in RASGRP2}

- Severe bleeding syndrome

- AR transmission

- Impaired LTA: ADP, Col, Cvx, AA, TRAP

- Positive response to PMA

- $\alpha \mathrm{llb} \beta 3$ present but defective activation

\section{Leukocyte Adhesion Deficiency III: Defects in FERMT3 encoding Kindlin3, activator of $\beta 3, \beta 2, \beta 1$}

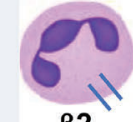

- Severe bleeding syndrome

- Severe infections, leukocytosis, +/- osteopetrosis

- AR transmission

- Absence or reduced LTA for all agonists

- $\alpha \mathrm{llb} \beta 3$ present but defective activation

Figure 2. Loss of CalDAG-GEFI and kindlin-3 function abrogates $\alpha$ llb $\beta 3$ activation. (A) A schematic representation showing examples of agonistic receptors and $\alpha \mathrm{llb} \beta 3$ in the resting and activated forms. Intracytoplasmic signaling pathways induced by the binding of appropriate ligands lead to parallel roles of CalDAG-GEFI and kindlin-3 in promoting $\alpha \mathrm{llb} \beta 3$ activation. CaIDAG-GEFI is critical for RAP1 activation both in the circulation and at sites of vascular injury. It responds to changes in cytoplasmic $\mathrm{Ca}^{2+}$ providing sensitivity and speed to the activation response; its absence leads to a Glanzmann thrombasthenia-like phenotype. Kindlin-3 binds directly to $\beta$-integrin cytoplasmic tails in platelets but also in white blood cells, explaining the susceptibility to infections and immune disorders in its absence. (B) Key elements of the syndromes resulting from RASGRP2 and FERMT3 defects are summarized. Bleeding in both cases can be very severe but defects in FERMT3 are syndromic and life-threatening. TRAP: thrombin receptor agonist peptid; PAR: protease activated receptor; Cvx: convulxin; GPVI: glycoprotein VI; TXA2: thromboxane A2; PLC $\beta / \gamma$ : phospholipase $C \beta / \gamma$; DAG: diacylglyerol: CalDAG-GEFI: calcium and diacylglycerol-regulated guanine nucleotide exchange factor I; RAP1: RAS-related protein 1; RD: related disease; AR: autosomal recessive; LTA: light transmission aggregometry; ADP: adenosine triphosphate; Col: collagen; Cvx: convulxin; AA: arachidonic acid; PMA: phorbol 12-myristate 13-acetate. 


\section{Defect of platelet procoagulant activity: Scott syndrome}

The original patient reported many years ago in New York had impaired platelet procoagulant activity and fibrin formation but other platelet functions were normal..$^{35}$ The affected gene ANO6 (also called TMEM16F) was discovered in 2010 when a constitutively active mutant was identified in a cDNA library obtained from a Ba/F3 cell line overexposing phosphatidylserine on the cell surface; a homozygous deleterious variant of $A N O 6$ in a patient with Scott syndrome validated the findings. ${ }^{36}$

\section{Definition}

Scott syndrome is characterized by autosomal recessive transmission, a lack of phosphatidylserine exposure and phosphatidylserine-bearing microparticle production from platelets and red blood cells. ${ }^{37,38}$ Loss of $\mathrm{Ca}^{2+}$-dependent binding of the intrinsic tenase (FVIIIa, IXa, X) and prothrombinase (FVa, Xa, prothrombin) complexes results in reduced thrombin generation.

\section{Clinical phenotype}

Only six cases of Scott syndrome have been detailed and all are women..$^{39}$ Bleeding is predominant after surgery or trauma; menorrhagia and post-partum hemorrhage are marked. Although spontaneous mucocutaneous bleeding is rare, it was severe in one young woman and included epistaxis, gum and gastrointestinal bleeding. ${ }^{39}$

\section{Biological phenotype}

The major diagnostic clues are elevated residual levels of prothrombin in sera and a marked defect of platelet procoagulant activity. Full diagnosis requires flow cytometry measurements of platelet phosphatidylserine exposure (annexin V-binding) and microparticle release upon activation by thrombin in combination with collagen or by the ionophore A23187.40 Loss of mitochondrial membrane potential, a major factor in phosphatidylserine exposure, late phase procoagulant ballooning and capping of adhesive proteins all still occur but may be reduced. Caspasedependent apoptotic or necrotic pathways of phosphatidylserine expression are normal. ${ }^{40}$ Platelet numbers, morphology, adhesion, secretion and aggregation are largely unaffected.

\section{Genotype}

Gene variants of ANO6 encoding a multi-pass transmembrane protein that is an essential component of the $\mathrm{Ca}^{2+}$-dependent "scramblase" activity cause Scott syndrome ${ }^{39}$ For the original patient a homozygous variant at a splice acceptor site in intron 12 resulted in a premature stop codon. ${ }^{36}$ Two French siblings showed compound heterozygosity for a large deletion of exons 1-10 in one allele and a premature stop codon on the other. ${ }^{41}$ Compound heterozygosity with premature termination was also seen in a Welsh family. ${ }^{42}$ All mutations result in abrogated TMEM16F expression.

\section{Ephrin type-B receptor 2-related disorder}

Recently, we demonstrated that defects in Ephrin type$B$ receptor 2 (EPHB2) cause a bleeding syndrome and IPD in two siblings from a consanguineous French family. ${ }^{43}$

\section{Definition}

Recurrent bleeding, normal platelet counts but abnormal function were linked to a variant of $E P H B 2$, encoding a member of the EPH receptor family of transmembrane tyrosine kinases. The molecular basis of this IPD confirms a specific role for EPHB2 in platelet function via tyrosine phosphorylation of intermediates involved in GPVI and G-protein-coupled receptor-mediated signaling.

\section{Clinical phenotype}

Both affected family members showed excessive spontaneous subcutaneous and heavy bleeding upon minor wounds. ${ }^{43}$ One sibling developed anemia after chronic gastrointestinal bleeding requiring iron supplementation. Due to its rarity the clinical phenotype remains poorly defined.

\section{Biological phenotype}

Ephrin receptors consist of a $\mathrm{N}$-terminal glycosylated ligand-binding domain, a transmembrane region, and an intracellular kinase domain. Interactions largely occur between neighboring cells; studies using mice revealed a role in thrombus formation and in both contact-dependent and -independent signaling. ${ }^{43}$ Platelets from our family showed decreased aggregation and secretion in response to $\mathrm{ADP}$, arachidonic acid, collagen, and analogs of thromboxane A. The mutation did not affect EPHB2ephrin interactions but phosphorylation of Lyn, Syk and FcR $\gamma$, the initial steps in GPVI signaling and of Src were drastically impaired as was inside-out $\alpha I I b \beta 3$ activation.

\section{Genotype}

A homozygous missense variant ( $p . R 745 C$ ) in the $E P H B 2$ gene was identified by whole exome sequencing in both siblings; their asymptomatic parents were heterozygous. The p.R745C substitution is located within the tyrosine kinase domain.

\section{P2Y12 receptor-related disorder}

The use of ticlopidine as an anti-platelet agent in the 1970s showed the benefit of blocking the interaction between ADP and platelets in anti-ischemic treatment. ${ }^{44}$ The recognition in 1992 of an Italian family with a ticlopidine-like platelet function profile and in 1995 of a French family with a similar defect was crucial to identifying how ADP activates platelets. ${ }^{45,46}$ Some 20 years later only a few such families have been identified.

\section{Definition}

P2Y12-related disease affects the full aggregation response of platelets to $\mathrm{ADP}$ and the stabilization of aggregates. Human platelets possess two ADP receptors that act in synergy: (i) P2Y1, a G--coupled receptor, which initiates platelet shape changes and ADP-induced aggregation through the mobilization of internal $\mathrm{Ca}^{2+}$ stores, and (ii) P2Y12, a G-coupled receptor linked to adenylyl cyclase and phosphoinositide 3-kinase activation (Figure 3).

\section{Clinical phenotype}

The disease is inherited in an autosomal recessive manner and is manifested clinically as moderate to severe mucocutaneous bleeding, including after surgery. ${ }^{45,46}$ Beyond the classical forms, a family with severe hemorrhage has been recently observed with autosomal domi- 
nant transmission; other cases with a monoallelic form have mild bleeding. ${ }^{47,50}$

\section{Biological phenotype}

ADP, even at high doses, fails to induce full and irreversible platelet aggregation. With other agonists such as thrombin receptor agonist peptide (TRAP), the snake venom protein convulxin or ristocetin, platelet aggregation may remain partially reversible. A key feature is defective Gio-mediated inhibition of platelet adenylyl cyclase by ADP with loss of vasodilator-stimulated phosphoprotein (VASP) de-phosphorylation, readily evaluated in a diagnostic test. ${ }^{48}$ Variants can result in qualitative or quantitative defects of P2Y12, the latter can also be attributed to defective receptor recycling.

\section{Genotype}

The patient that we first described in 1995 has a two nucleotide deletion in the coding region of P2RY12 moving the reading frame before the introduction of a premature stop (p.I240fs*29). ${ }^{10}$ Subsequently described mutations with autosomal recessive transmission include those of the initially reported Italian family, heterozygous for two missense mutations, p.R2560 and p.R265W (Figure
3). ${ }^{48,49}$ Here, two asymptomatic family members carried the heterozygous p.R265W variant. This is important because recently a single allele p.R265P variant, affecting the same amino acid but with a different substitution, was associated with a severe phenotype and autosomal dominant transmission in an unrelated family (Figure 3). ${ }^{47}$ Significantly, platelet mRNA for this allele was three-fold overexpressed, limiting wild-type homodimer formation (key to ADP-receptor signaling) and introducing a dominant-negative effect. ${ }^{47}$ Other mutations with a single affected P2RY12 allele and mild bleeding in families with autosomal dominant transmission are shown in Figure $3 .{ }^{48}$ Missense mutations allowing normal P2Y12 synthesis and affecting domains close to or part of the ADP-binding pockets cause qualitative defects (Figure 3). ${ }^{48,50}$ Special mention should be made of a novel cytoplasmic domain p.P341A variant affecting the PDZ-binding domain and causing abnormal endosomal recycling of platelet internal pools leading to a surface deficit of P2Y12. ${ }^{51}$ Interestingly, p.R122C and p.K174E P2RY12 variants have been associated with an intronic polymorphism within FR2 (encoding PAR-1) in a patient with chronic bleeding and in a patient with type 1 von Willebrand disease showing that hemorrhage can be part of a complex trait. ${ }^{52,53}$
A

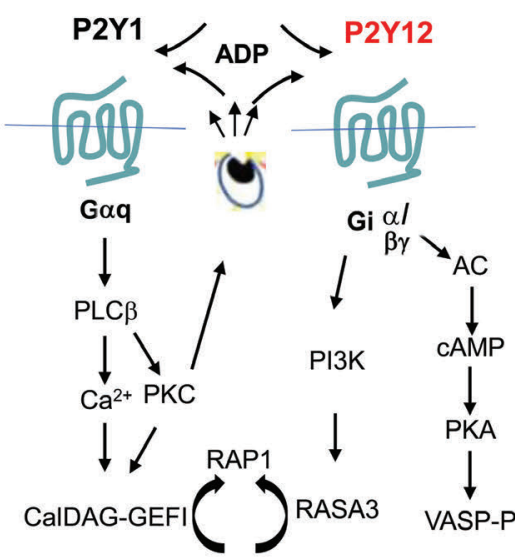

D

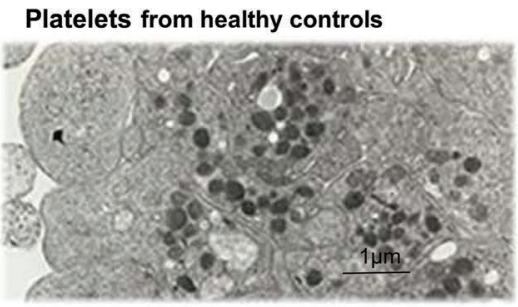

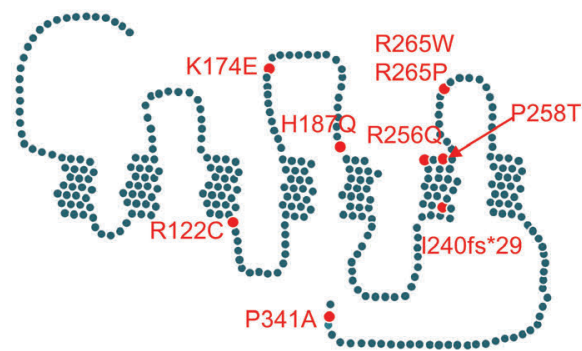

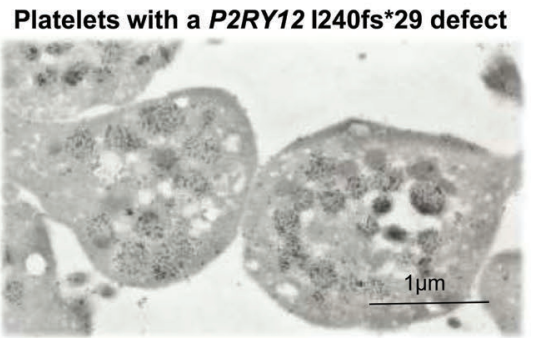

C

Severe phenotype-biallelic:
I240fs*29: decreased ligand binding
R122C: decreased ligand binding,
defect of recycling
H187Q: normally expressed but
dysfunctional
R256Q/R265W: normally expressed
but dysfuntional

Severe phenotype-monoallelic R265P: normal ligand binding, defective signalling

Figure 3. G-protein-coupled ADP receptors and signaling pathways highlighting $P 2 R Y 12$ variants and their different subgroups. (A) A schematic representation of ADP-induced signaling pathways. Binding of extracellular ADP to the G-coupled P2Y1 receptor initiates aggregation whereas the G-coupled P2Y12 receptor enhances and sustains the platelet response. Specific signaling pathways are involved with PLCB and PI3K enabling both RAP1 activation and RASA3 inactivation; both are required for the formation of a stable hemostatic thrombus. The release of ADP from dense granule storage pools after protein kinase $C$ (PKC) activation contributes to the stabilization of thrombi. (B) The schematic representation shows the structure of P2Y12; variants reported as causal for a bleeding syndrome are highlighted (red spots). (C) Summarizes the genotype/phenotype relationship when the variants are regrouped according to bleeding severity and their mode of transmission. The first group consists of patients with autosomal recessive transmission and platelets showing defects of both the binding of ADP analogs and/or receptor cycling. The p.H187Q variant located in the fifth transmembrane domain has normal receptor expression but suppressed function..$^{50}$ Interestingly p.R256 has a side chain that inserts into a hydrophobic pocket and in docking models it potentially makes contact with the phosphate groups of ADP:52 p.R265W impairs receptor activation and probably alters the conformational state of the receptor. Significantly, a severe phenotype-monoallelic form has a different amino acid substitution on the same residue, p.R265P associated with an increased expression of mutated mRNA and an impaired wild-type homodimer formation, possibly accounting for the bleeding severity. The third subgroup has a mild phenotype and monoallelic expression of mutations that affect receptor function: note that p.P341A located in the PDZ intracellular domain is associated with both abnormal ligand binding and a defect of re-sensitization of the receptor after ADP agonist-induced desensitization. (D) Electron microscopy of platelet aggregates stimulated with $10 \mu \mathrm{M}$ ADP examined at the peak of aggregation. For the control the platelets are in close contact with some of the cells having lost their granule content. For our patient with the p.I240fs* 29 mutation, platelets remain loosely bound and their granule contents are still present, as shown by the immunogold (black dots) localization of fibrinogen. 


\section{Antiplatelet therapy}

P2Y12 identification was key to the development of nextgeneration therapies including the orally available thienopyridines (clopidogrel and prasugrel). These are prodrugs requiring cytochrome P450-based conversion to a short-lived active metabolite that binds covalently to P2Y12 although drug-resistance to clopidogrel can affect up to a third of patients. ${ }^{14}$ Ticagrelor and cangrelor are direct-acting and rapidly reversible antagonists; cangrelor given intravenously has the advantage of acting immediately.

\section{Other platelet primary receptor defects}

\section{Glycoprotein VI-related disease}

Rare inherited autosomal recessive defects of the GP6 gene cause a mild bleeding syndrome. GPVI is a receptor for collagen as well as other extracellular matrix components and, as recently identified, fibrin. ${ }^{54,55}$ A member of the immunoglobulin superfamily, GPVI forms a non-covalent complex with FcR $\gamma$ and acts in synergy with integrin $\alpha 2 \beta 1$. Early evidence of an inherited GPVI deficiency came from a Japanese woman with lifelong although mild mucocutaneous bleeding and platelets refractory to collagen despite responding to other agonists; immunological studies confirmed the specific absence of GPVI ${ }^{56}$ The first genotyped patients with GP6 variants belonged to families from France and Belgium with autosomal recessive compound heterozygous mutations. 57,58 However, most studies have centered on a cluster of patients from Chile with a homozygous 2 bp insertion followed by a stop at position $242 .{ }^{59}$ All evidence suggests a founder effect. The Chilean patients had mild bleeding and heterozygous family members were asymptomatic. A defective platelet interaction with fibrin and immobilized fibrinogen helps to explain the diminished thrombus build up under flow..$^{58}$

\section{Thromboxane prostanoid type $\alpha$ receptor-related disease}

The TBXA2R gene encodes the thromboxane prostanoid type $\alpha$ receptor (TP $\alpha$ ), the major thromboxane A2 (TXA.) receptor on platelets. ${ }^{60}$ Its activation leads to $\mathrm{Ca}^{2+}$ mobilization and platelet aggregation. It associates mainly with $\mathrm{G}_{4}$ and principally modulates platelet activation through the PLC $\beta$ pathway. Platelet aggregation is characterized by a decreased response to arachidonic acid or TXA. analogs such as U46619 and I-BOP. ${ }^{61}$ From as early as 1994, Japanese families were described with a bleeding disorder due to a non-responsive TP $\alpha$ receptor. ${ }^{62,63} \AA$ p.R60L variant in the first intracytoplasmic loop of TPa with autosomal dominant transmission predominated, but it was homozygous in one member with mild mucocutaneous bleeding. Globally, three more families were later reported with autosomal dominant transmission; two had missense mutations with a dominant-negative effect linked to impaired receptor dimerization while a third had a frameshift variant, a stop codon and reduced TP $\alpha$ expression. ${ }^{60,64}$

\section{Antiplatelet therapy}

The apparent preservation of hemostasis in the absence of GPVI has prompted research for anti-ischemic drugs and, in particular, treatment for stroke..$^{14}$ Revacept is a recombinant soluble dimeric GPVI-Fc fusion protein blocking GPVI-reactive sites in collagen and is the object of ongoing clinical trials. Fab fragments of a monoclonal antibody blocking GPVI, ACT017, have exhibited excellent safety and tolerability profiles in a phase 1 study in humans..$^{65}$ An exciting challenge for anti-GPVI drugs will be to block thrombus build up through inhibition of the GPVI-fibrin interaction while preserving the initial interaction with collagen. Anti-GPVI agents may also have a role in cancer therapy by inhibiting platelet-tumor cell interactions; galactin-3 is a novel counter-receptor for GPVI on tumor cells. ${ }^{66}$ Attempts at treating ischemic disease based on inhibition of TXA2R have largely failed compared to the efficiency of aspirin and related drugs. ${ }^{14}$

\section{Classic dense granule defects}

Much information has been obtained from studies on disorders of platelet lysosome-related organelles. ${ }^{6,68}$

\section{Hermansky-Pudlak syndrome}

Hermansky-Pudlak syndrome (HPS) is named after the Czechoslovakian physicians who in 1959 described two patients with oculocutaneous albinism, prolonged bleeding and pigmented macrophages in the bone marrow. ${ }^{6}$ Many of the advances regarding HPS have been linked to the numerous mouse and other animal models of storage pool diseases. ${ }^{68,69}$

\section{Definition}

HPS is a heterogeneous autosomal recessive multisystem disorder resulting from defects of ten genes encoding proteins essential for the biogenesis of platelet dense granules, a member of the lysosomal-related organelle family. ${ }^{6-69}$ Association with albinism reflects defects in the biogenesis of melanosomes in the melanocytes of the skin, hair and choroid of the eye while pigment epithelial cells of the retina can also be affected.

\section{Clinical phenotype}

The bleeding diathesis includes easy bruising, epistaxis, gingival bleeding, menorrhagia, postpartum hemorrhage and prolonged bleeding after surgery. ${ }^{67}$ Platelet transfusions prevent the hemorrhagic risk during surgery, while tranexamic acid is often used preventively or to stop moderate bleeding. Oculocutaneous albinism involves hypopigmentation of the skin and hair associated with characteristic ocular findings. Granulomatous colitis, neutropenia, immunodeficiency and fatal pulmonary fibrosis can feature according to the subtype. ${ }^{67-69}$

\section{Biological phenotype}

Platelet aggregation is characterized by an impaired second wave..$^{88,69}$ The specific absence of dense granules means that the platelet secretory pool of ADP, ATP, serotonin, calcium, and polyphosphate is reduced or lacking. Dense granules can be evaluated by whole mount electron microscopy due to their opacity to electrons (Figure 4). Total platelet ADP and ATP and the secretion of ATP during platelet aggregation is now mostly measured by bioluminescence. Quantifying mepacrine uptake by flow cytometry is an indirect method for assessing dense granule content. Granule secretion can also be measured by flow cytometry based on the translocation of P-selectin and lysosomal-associated membrane protein (LAMP-3, CD63) to the platelet surface; exposure of LAMP-3 can be spontaneous. 


\section{Genotype}

Identification of pathogenic variants for HPS involves ten subtypes (HPS1-10) and ten genes: $A P 3 B 1, A P 3 D 1$, $B L O C 1 S 3$ encoding for BLOS-3, BLOC1S6 encoding for pallidin, DTNBP1 encoding for dysbindin, HPS1, HPS36. ${ }^{69-71}$ All of the genes encode subunits organized in four multi-subunit protein complexes, named biogenesis of lysosome-related organelles complex (BLOC)-1, -2 and -3 and the adaptor protein-3 complex (AP-3). ${ }^{67-71}$ The HPS phenotype is related to the BLOC complex affected (Figure 4). BLOC-1 consists of eight subunits of which dysbindin (HPS7), BLOS-3 (HPS8) and pallidin (HPS9) are mutated in rare patients with a mild or absent bleeding diathesis and variable hypopigmentation. HPS3, HPS5, and HPS6 are subunits of BLOC-2; mutations in these genes are more frequent than those in the BLOC-1 and affected individuals have a mild clinical phenotype with a bleeding syndrome and hypopigmentation only. HPS1 and HPS4 are subunits of BLOC-3; mutations in these cases are predominantly associated with severe manifestations (severe oculocutaneous albinism, pulmonary fibrosis, granulomatous colitis). BLOC-3 defects are the most frequent form of HPS with p.His497Glnfs*90 in HPS1, the first HPS mutation to be discovered; this form is common in Puerto Rico. ${ }^{67}$ The AP-3 complex has four subunits with $A P 3 B 1$ encoding 33 A mutated in HPS-2 and AP3D1 encoding AP-3 $\delta$ mutated in HPS-10. AP-3 is important for dense granule biogenesis and protein delivery to the forming granule (e.g., the serotonin transporter, VMAT2).69-72 Variants of AP3B1 are said to cause HPS type II. Interestingly, Enders et al. detected a homozygous nonsense mutation in $A P 3 B 1$ together with a heterozygous bystander $R A B 27 A$ mutation in a child with bleeding, albinism, developmental delay and a susceptibility to infections; HPS type II was diagnosed rather than Griscelli syndrome as would indicate a RAB27A mutation. ${ }^{72} \mathrm{HPS}-10$ is a very rare form of HPS characterized by partial oculocutaneous albinism, bleeding, neutropenia and immunodeficiency. Defective protein disulfide isomerase release from platelets and endothelial cells in HPS contributes to the impaired thrombus formation and could represent a novel target for antithrombotic drugs. ${ }^{73}$

\section{Chediak-Higashi syndrome}

The most important clinical problem of patients with Chediak-Higashi syndrome is immunodeficiency with life-
A

\begin{tabular}{|l|}
\hline HPS7 (Dysbindin), \\
HPS8 (BLOS3), \\
HPS9 (Pallidin) \\
Little or no bleeding \\
and hypopigmentation \\
\hline HPS3, HPS5, HPS6 \\
Mildly affected \\
patients \\
Mild bleeding \\
syndrome \\
OCA but variable \\
hypopigmentation \\
\hline \\
\hline HPS1, HPS4 \\
Severely affected \\
patients \\
OCA \\
Bleeding syndrome \\
Pulmonary fibrosis \\
Granulomatous colitis \\
\hline HPS10 IAP3D1 \\
\hline Defect of $\delta$ subunit \\
Bleeding diathesis \\
OCA \\
Immunodeficiency \\
Neutropenia \\
\hline
\end{tabular}
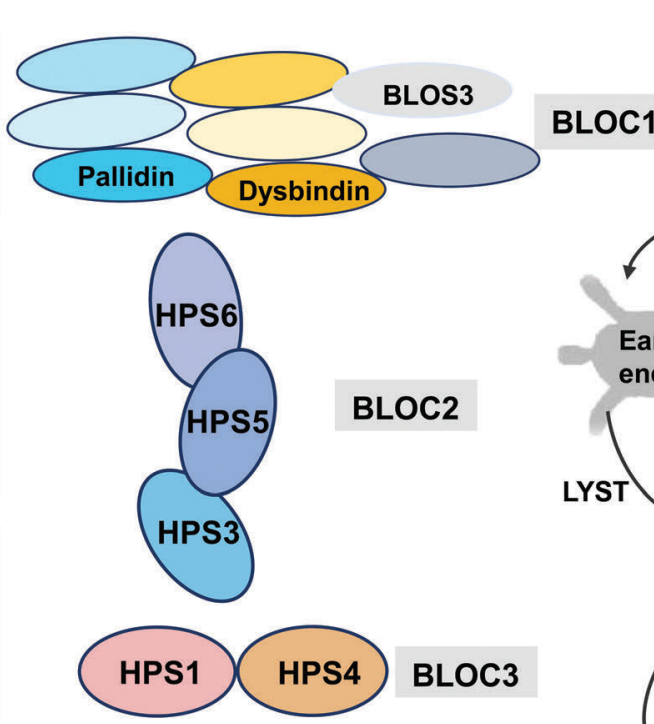

BLOC3

Rab 32/38

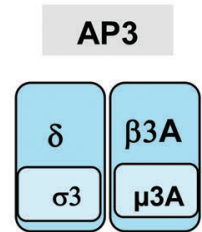

B

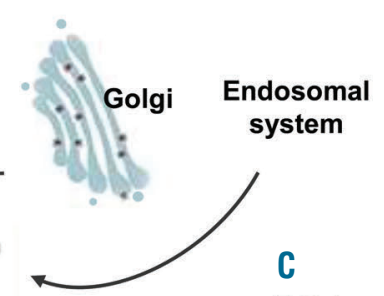

DG in controls

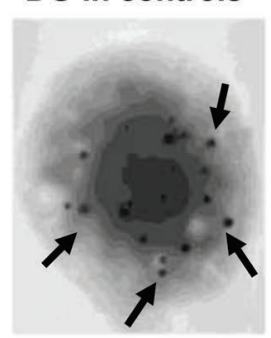

Dense granule

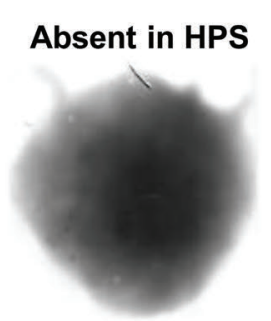

Figure 4. Hermansky-Pudlak syndrome. Syndromic platelet defect resulting from the abnormal biogenesis of dense granules with an autosomal recessive inheritance. (A) Summarizes the genotype/phenotype relationship of different types of Hermansky-Pudlak syndrome (HPS) regrouped according to the four multi-protein complexes involved in different steps of lysosome-related organelle (LRO) biogenesis including vesicle formation and/or trafficking: BLOC1, 2 and 3 and AP-3 with each containing several subunits. Variants in HPS 7, 8 and 9 are causal in BLOC1 but with mild clinical consequences. For BLOC2, variants in HPS 3, 5 or 6 give syndromes of moderate severity; they are rare but a variant of HPS 3 occurs in Puerto Rican communities. The most frequent causes of HPS are BLOC3 defects (variants in HPS 1 or 4). The syndromes are severe and are associated with lung fibrosis and gastro-intestinal defects; in Puerto Rico a community is affected by a common HPS1 variant. In the last group, defects of AP-3 are associated with neutropenia and infections. (B) A scheme illustrates the major steps of granule biogenesis. Dense granules may derive from the endolysosomal system, including either early or late endosomes. As secretory granules the membrane constituents including membrane transporters come from the Golgi complex. A network of interconnected and functionally distinct tubular subdomains transports their cargoes along microtubule tracks from the endosomes. Tubules ferry contents from the trans-Golgi-network and the plasma membrane to the LRO, a system that requires the coordination of numerous effectors. Components stored in dense granules or associated with their membranes are shown. (C) Platelets from a control and a patient with HPS3 examined by electron microscopy as whole mounts are shown. The dense granules observed in controls as black spots are absent from the patient's platelet. AP-3: adaptor protein-3; BLOC: biogenesis of lysosome-related organelles complex; LRO: Iysosome-related organelle; OCA: oculocutaneous albinism; MVB: multivesicular body. 
threatening infections. There is mild bleeding with a partial to severe reduction of dense granules. ${ }^{67,69,74}$ It is a rare but fatal autosomal recessive disorder with multiple clinical features, including hypopigmentation of skin and hair, reduction of leukocytes, giant organelles in circulating granulated cells, and neurological dysfunction. Recurrent infections are associated with defective function of natural killer cells. Immune dysregulation often leads to lymphoproliferative histiocytosis with an accelerated phase that determines the prognosis. ${ }^{73}$ Platelet function defects resemble those seen in HPS. The LYST gene (also called CHS1) alone is responsible for this disease and a wide variety of mutations have been described. ${ }^{67,69,74}$ Chediak-Higashi syndrome is particularly prevalent in Puerto Rico. ${ }^{67,69}$ LYST is a member of the BEACH protein family and is required for sorting resident endosomal proteins into late multivesicular endosomes (Figure 4B). ${ }^{71,74}$

\section{Other defects involving platelet granules}

As well as the above disorders, qualitative defects can lead to decreased dense granule content, inability to secrete their contents or combined dense- and $\alpha$-granule deficiency. ${ }^{71,75,76}$ An absent second wave of aggregation in response to $\mathrm{ADP}$ and collagen is characteristic. This can be secondary to mutations of genes for membrane receptors: P2RY12, GP6, TBXA2R, EPHB2, G6b-B; or genetic defects often accompanied by thrombocytopenia (Online Supplementary Table S1). ${ }^{11}$ Applying next-generation sequencing procedures targeting 329 preselected genes, Leo et al. analyzed 18 patients including six with secretion defects, highlighting 49 genes not previously known to be causal of IPD. ${ }^{77}$ Gorski et al. performed a similar study using whole exome sequencing of 14 patients with bleeding caused by primary platelet secretion defects. ${ }^{78}$ Both studies exposed the complications of whole exome sequencing and next-generation sequencing when isolated gene variants are identified as potentially causal without statistical validation or comprehensive biological studies or usage of mouse models.

A specific condition with defective granule secretion from platelets is familial hemophagocytic lymphohistiocytosis, a rare primary immunodeficiency syndrome in which autosomal recessively inherited variants of UNC13D, STX11 and STYXBP2 can result in defects in the secretory machinery of dense bodies and $\alpha$-granules as well as lysosomes. ${ }^{79-82}$

\section{THERAPEUTIC TOOLS TO PREVENT OR TREAT BLEEDING SYNDROMES}

\section{DAILY LIFE}

\section{Preventive actions:}

- Provide a card to the patients indicating essential medical information to prevent or treat bleeding and with their bleeding score

- Establish a list of medications to avoid

- Recommend a life-style in line with the hemorrhagic risk e.g.avoid contact sports, etc.

- Recommend regular dental care, hormonal therapy to reduce menorrhagia

- Evaluation of the need of iron supplementation

\section{SURGERY}

Bleeding risk must be established by a multidisciplinary staff and a protocol planned

Moderate bleeding:
- Locally: compression, nasal packing, cold application
Systemic: anti-fibrinolytics (tranexamic acid, Amicar);
desmopressin
Severe bleeding:
- Transfer to a hospital center
- Platelet transfusions (HLA compatible, leukocyte-depleted;
but risk of iso-immunisation for patients with type I GT)
- Hemostatic compounds (e.g. rFVIla) for patients refractory to
platelet transfusions and/or at risk of iso-immunization
platelet transfusions and/or at risk of iso-immunization

Minor surgery and/or moderate bleeding risk

- Anti-fibrinolytics or desmopressin or both

Major surgery and/or an important bleeding risk

- Prophylactic platelet transfusions: HLA and/or HPA

compatible and/or rFVIla. Platelet transfusions can be used in combination with anti-fibrinolytics

\section{PREGNANCY - Evaluation of the risk of bleeding during delivery - Prophylactic platelet transfusions and/or anti-fibrinolytics \\ GT, Glanzmann thrombasthenia HLA, Human Leukocyte Antigens HPA, Human Platelet Antigens \\ LAD, Leukocyte Adhesion Deficiency}

\section{RECURRENT SEVERE BLEEDING WITH POOR RESPONSE TO TREATMENT}

- Cesarean section is managed as surgery
- Vaginal delivery, anti-hemorrhagic factor managed at the time
of delivery
- Spinal or epidural anesthesia are contraindicated in severe
forms
- No fetal blood sampling as there is a risk for the newborn
- Necessity of a post partum follow up for severe forms

Stem cell transplantation: GT, LAD-III

Gene therapy for GT patients on the horizon

Figure 5. Schema with management options for patients with inherited defects of platelet function. It is important to limit risks in daily life. It is also important to provide each patient with a card detailing the type of disorder and proposing the medication to be used according to the bleeding risk, in particular when platelet expert medical centers are unavailable to take charge of the patient's needs. While the main therapeutic approaches for all disorders, including those patients with Glanzmann thrombasthenia (GT), RASGRP2 (CaIDAG-GEFI)-related disease, and leukocyte adhesion deficiency III (LAD-III) syndrome for whom bleeding can be severe, are similar, some situations (e.g., isoantibody formation in GT) or infections in LAD-III syndrome need special care. Surgery requires a multidisciplinary consensus to evaluate the risk of bleeding, the benefit-risk ratio of prophylaxis, and to assess therapeutic efficiency. Pregnancy is always a challenge, from women with mild bleeding risks for whom minimal measures are needed to those with a severe bleeding history and for whom maximal prophylactic care is required. Here again, the management must be planned between obstetricians, anesthetists and hematologists. The contraindication of epidural or spinal anesthesia for those with mild risk remains a difficult problem, as is the choice of vaginal delivery or Cesarean section for the most severe forms. In the figure, it is noted that for mild bleeding risk, an antifibrinolytic medication or desmopressin is preferred as the first line of bleeding prevention and that platelet transfusions should be considered only when these approaches are insufficient. There is a risk of allo- or iso-immunization which, if it occurs, can be a lifelong handicap, and recombinant activated factor VII is increasingly recommended. Finally, stem cell transplantation is reserved for young patients with recurrent, severe bleeding that fails to respond to standard treatments and when the survival of the patient is at risk. Gene therapy is not yet an option for the disorders covered in this review but will probably become available in the future. 


\section{Cytosolic signaling pathways}

Rao and his colleagues were pioneers in identifying candidate proteins in patients with mild bleeding diatheses deficient in key signaling pathways and second messengers. ${ }^{83} \mathrm{G} \alpha q$, PLC- $\beta 2$, as well as defects in $\mathrm{Ca}^{2+}$-mobilization and protein kinase C-induced phosphorylation were highlighted. Abnormalities extended to granule secretion as well as $\alpha I \operatorname{Ilb} \beta 3$ activation. However, most of the early patients still await full genetic analysis. We have chosen to highlight three genes involved in arachidonic acid metabolism in platelets.

The first is a defect of PLA2G4A encoding cytosolic PLA2 in three families. In the first family compound heterozygous missense mutations induced marked structural changes within cPLA2. In the second family heterozygous p.S111P and p.R $485 \mathrm{H}$ missense variants respectively affected cPLA2 trafficking and abrogated the enzyme's catalytic activity; while for the third family a homozygous p.D575H PLA2G4A variant was present. ${ }^{84.86}$ In all three cases, platelet aggregation and dense granule secretion with collagen and ADP were impaired; gastrointestinal bleeding was a feature.

An inherited defect of cyclooxygenase-1 (COX-1) is more specifically linked to defective platelet aggregation with arachidonic acid and absence of the second wave response to epinephrine, ADP and collagen. While failing to respond to arachidonic acid, platelets aggregate normally with TXA agonists. Several such patients with mild bleeding have been reported either with autosomal dominant or, more recently, autosomal recessive transmission of variants in PTGS1 ${ }^{87-89}$ Patients may lack COX1 or have a functionally defective but normally expressed enzyme. Bastida et al., using a high-throughput sequencing gene panel, found a heterozygous variant with an aspirin-like platelet functional defect linked to a heterozygous p.N143S missense mutation in PTGS1. ${ }^{88}$ Very recently, whole genome sequencing helped to identify a homozygous missense variant (p.W322S) in a large consanguineous family of Iranian descent with mild bleeding. ${ }^{89}$

The third disease is Ghosal syndrome, a disorder with increased bone density that was linked to a deletion mapped to chromosome 7q33/34. The deletion includes TBXAS1, the gene for thromboxane synthase, a terminal enzyme in the arachidonic acid cascade converting prostaglandin $\mathrm{H} 2$ into TXA. A key fiding was homozygous missense mutations alone in TBXAS1 in consanguineous families with Ghosal syndrome in ethnic groups; the affected residues were all highly conserved..$^{90}$ Platelets from the patients had reduced aggregation and secretion in response to arachidonic acid; in contrast the response to U46619 directly activating TP $\alpha$ was normal. A role for TXA in bone remodeling is also indicated. Somewhat surprisingly, none of the patients had a bleeding diathesis (distinguishing them from patients with congenital defects of TBXA2R).

\section{Therapy}

The management of IPD involves both prevention of bleeding and treatment of mild and severe bleeding episodes and differs little for disorders of platelet count with the exception that the recent use of thrombopoietin mimetics is not applicable. ${ }^{11}$ As detailed in Figure 5, strategies involve the maintenance of a lifestyle that minimizes risk and being prepared in case of an emergency. Procedures range from local measures to the use of platelet transfusions or recombinant activated FVII to stop major bleeding as well as the establishment of and adherence to standardized protocols for prophylaxis prior to surgery or childbirth. ${ }^{15,91-93} \mathrm{~A}$ special case is type I GT in which the absence of $\alpha \operatorname{Ilb} \beta 3$ can lead to the formation of isoantibodies, making patients refractory to normal platelets.

\section{Conclusions}

Of the disorders covered by this review, GT is the most frequent and widely screened disease..$^{12,15}$ Genotyping has now identified several hundred disease-causing mutations in a constantly changing spectrum, so the classification of patients into type I and type II subgroups based on residual platelet $\alpha I i b \beta 3$ content should be updated to take into account mutation analysis. ${ }^{18,19}$ From 2001, the year in which P2RY12 was first characterized, ${ }^{10}$ newly identified genes include FERMT3, ANO6, RASGRP2 and EPHB2 thereby expanding the gene repertoire for IPD. $25,26,33,3,4,36,43$ The development of next-generation sequencing platforms targeting IPD genes, ${ }^{6,88}$ together with widening access to whole exome sequencing, $4,7,8$ and now whole genome sequencing, ${ }^{9}$ has both increased the number of patients with a genetic diagnosis and the speed at which this is performed. The multiplication of data has underlined the great diversity of variants responsible for gene dysfunction, the rarity of hot-spot mutations, the frequency of compound heterozygosity within the same gene (limiting the notion of consanguinity for recessive diseases); and raised the likelihood of additive effects of heterozygous variants on different genes modulating the phenotype. It is also worthy of mention that some inherited thrombocytopenias with associated functional platelet defects (Online Supplementary Table SI) may not have complete penetrance and some patients may therefore not be thrombocytopenic (e.g., those with mutations of RUNX1 and FLI1). ${ }^{11}$ The increasing understanding of the gene spectrum causing IPD is leading to better care of patients and it should be underlined how major anti-ischemic treatments have been initiated or improved as a result of this.

\section{Future strategies}

Despite the progress in gene identification a significant proportion of patients still fail to be genotyped. One successful strategy for the identification of causal genes in patients with inherited thrombocytopenia was by comparison with mouse models with similar phenotypes: ${ }^{11,69}$ Another approach is ongoing screening of local whole exome or whole genome sequencing databases of patients for variants of each newly published IPD gene. A third strategy involves screening large families or those with consanguinity, as done for RASGRP2 and EPHB2, or statistical analysis of large cohorts of patients, aligning variant detection in unrelated families with a similar phenotype. ${ }^{26}$ The final proof that variants in new genes are causal will still require their expression in heterologous cells, the use of in silico modeling to assess changes in protein structure, 
or their reproduction in mouse, zebrafish or other animal models. ${ }^{3,494}$ When no genetic diagnosis has been achieved with standard approaches, gene analysis should be expanded to evaluate complex copy number variations, deep variants in non-coding regions and secondary defects involving the action of microRNA or retrotransposons, as we have detailed elsewhere. ${ }^{11}$

Currently the diagnosis of IPD is based largely on the concept of a monogenic heritable platelet disease, but a proportion of these diseases may be di- or polygenic in origin. Families with unexplained heritability may have unrecognized variants or other changes in regulatory regions in combinations that only advanced technologies may help to resolve. Thus in a large cohort of patients with primary immunodeficiency, genome-wide association studies have revealed loci that modulate platelet function with the co-localization of and interplay between novel high-penetrance monogenic variants and common variants..$^{95}$ It is reassuring that IPD without thrombocytopenia are not associated with a propensity to develop hematological malignancies or bone marrow aplasia or fibrosis, as in some inherited thrombocytopenias such as RUNX1-related disease and ETV6-related disease.

Current advances suggest the need to redefine the circuit for patient screening from the first consultation. An information-gathering first consultation, blood cell counts and basic coagulation screening remain essential as is assigning a bleeding score and determining whether the platelet function abnormalities are isolated or syndromic. ${ }^{96}$ But flow charts with extensive biological testing in order to select the gene(s) to analyze need to be revisited and the choice of extensive biological testing before genotyping questioned. Platelet aggregation, flow cytometry and the examination of blood smears provide early information to guide the diagnosis. ${ }^{75,97}$ Nevertheless, when clinical and biological data are in favor of an IPD, in selected cases upfront DNA analysis may save time, money and improve patients' care: however longitudinal studies are required to substantiate this expectation. For patients without access to a specialized platelet center, sending blood and DNA samples to expert centers is recommended. Validation of novel variant(s) on next-generation sequencing targeted gene platforms or after whole exome or whole genome sequencing requires confirmation by co-segregation or other studies as discussed above and it is here that selected biological phenotyping may be necessary.

As part of this roadmap, national centers regrouping platelet experts have a key inter-connecting role between the patients, local hematology laboratories and genomic platforms. In France, our creation of a Reference Center for IPD, led to the organization, on a national basis, of platelet studies with European links to next-generation sequencing and the preparation of personalized followup both for the patient and the local general practitioner. In this context it is indispensable that the medical personnel directly responsible for the patient remain in control of the diffusion of information both to the patient and in the scientific literature and especially take into account ethical considerations. ${ }^{98}$ In everyday clinical practice a patient-centered approach governed by the overarching principle of patient utility versus in-depth, detailed laboratory and genetic characterization is acceptable and in generally sufficient for patients' care. ${ }^{99}$ On the other hand, our understanding of these disorders cannot be expanded without advanced research involving modern technologies. Here, informed explicit collaboration of the patient should be obtained.

\section{Disclosures}

No conflicts of interests to diclose.

\section{Contributions}

All the authors participated in the manuscript preparation. $P N$ and ATN supervised the writing of the text.

\section{Acknowledgment}

We thank Xavier Pillois for his contribution to the section on GT and for the Pymol model of $\alpha I I b \beta 3$.

\section{References}

1. Nurden P, Nurden AT. Congenital disorders associated with platelet dysfunctions. Thromb Haemost. 2008;99(2):253-263.

2. Favier R, Raslova H. Progress in understanding the diagnosis and molecular genetics of macrothrombocytopenias. Br J Haematol. 2015;170(5):626-639.

3. Heremans J, Freson K. High-throughput sequencing for diagnosing platelet disorders: lessons learned from exploring the causes of bleeding disorders. Int J Lab Hematol. 2018;40(Suppl):89-96.

4. Lentaigne C, Freson K, Laffan MA, et al. Inherited platelet disorders: towards DNAbased diagnosis. Blood. 2016;127(33):28142823.

5. Johnson B, Lowe GC, Futterer J, et al. Whole exome sequencing identifies genetic variants in inherited thrombocytopenia with secondary qualitative function defects. Haematologica. 2016;101(10):1170-1179.

6. Simeoni I, Stephens JC, Hu F, et al. A highthroughput sequencing test for diagnosing inherited bleeding, thrombotic and platelet disorders. Blood. 2016;127(23):2791-2803.

7. Downes K, Megy K, Duarte D, et al.
Diagnostic high-throughput sequencing of 2,396 patients with bleeding, thrombotic and platelet disorders. Blood. 2019;134(23): 2082-2091.

8. Megy K, Downes K, Simeoni I, et al. Curated disease-causing genes for bleeding, thrombotic, and platelet disorders Communication from the SSC of the ISTH. J Thromb Haemost. 2019;17(8):1253-1260.

9. Gunay-Aygum M, Zivony-Elboum Y, Gumruk F, et al. Gray platelet syndrome: natural history of a large patient cohort and locus assignment to chromosome $3 p$. Blood. 2010;116(23):4990-5001.

10. Hollopeter G, Jantzen AM, Vincent D, et al. Identification of the platelet ADP receptor targeted by antithrombotic drugs. Nature. 2001;409(6817):202-207.

11. Nurden A, Nurden P. Inherited thrombocytopenias: history, advances and perspectives. Haematologica. 2020;105(8):1-16.

12. Nurden AT, Fiore M, Nurden P, Pillois X. Glanzmann thrombasthenia: a review of ITGA2B and ITGB3 defects with emphasis on variants, phenotypic variability, and mouse models. Blood. 2011;118(23):59966005

13. Coller BS, Shattil SA. The GPIIb/IIIa (integrin $\alpha I I b \beta 3$ ) odyssey: a technology-driven saga of a receptor with twists, turns, and even a bend. Blood. 2008;112(8):3011-3025

14. Mackman N, Bergmeier W, Stouffer GA Weitz JI. Therapeutic strategies for thrombosis: new targets and approaches. Nat Rev Drug Disc. 2020;19(5):333-352.

15. Botero JP, Lee K, Branchford BR, et al ClinGen Platelet Disorder Variant Curation Expert Panel. Haematologica. 2020;105(4): 888-894.

16. Nurden AT. Acquired Glanzmann thrombasthenia: from antibodies to anti-platelet drugs. Blood Rev. 2019;36:10-22.

17. Nurden AT, Pillois $X$, Fiore $M$, et al Expanding the mutation spectrum of the $\alpha I l b \beta 3$ integrin in Glanzmann thrombasthenia: screening of the ITGA2B and ITGB3 genes in a large international cohort. Hum Mutat. 2015;36(5):548-61.

18. Nurden AT, Pillois X. ITGA2B and ITGB3 gene mutations associated with Glanzmann thrombasthenia. Platelets. 2018;29(1):98101.

19. Pillois X, Nurden AT. Linkage disequilibrium amongst ITGA2B and ITGB3 gene variants in patients with Glanzmann thrombasthenia confirms that most disease-causing mutations are recent. Br J Haematol. 2016;175(4):686-695. 
Inherited platelet function disorders

20. Takagi J, Pere BM, Walz T, Springer TA. Global conformational rearrangements in integrin extracellular domains in outside-in and inside-out signaling. Cell. 2002;110(5): 599-611.

21. Zhu J, Zhu J, Springer TA. Complete integrin headpiece opening in eight steps. J Cell Biol. 2013;201(7):1053-1068.

22. Gullet B, Bayart S, Pillows X, Nurden P, Caen JP, Nurden AT. A Glanzmann thrombasthemia family associated with a TUBB1-related macrothrombasthenia. J Thromb Haemost. 2019;17(12):2211-2215

23. Jamasbi J, Ayabe K, Goto S, Nieswandt B, Peter K, Lies W. Platelet receptors as herapeutic targets: past, present and future. Thromb Haemost. 2017;117(7):1249-1257.

24. Rule V, Agueznai M, Sabatier R, et al. Safety and efficacy of IIb/IIIa inhibitors in combination with highly active oral antiplatelet regimens in acute coronary syndomes: a meta-analysis of pivotal trials. Platelets. 2017;28(2):174-181.

25. Canault M, Ghalloussi D, Grosdidier C, et al. Human CalDAG-GEFI gene (RASGRP2) mutation affects platelet function and causes severe bleeding. J Exp Med. 2014;211(7): 1349-1362.

26. Canault M, Alessi MC. RASGRP2 structure, function and genetic variants in platelet pathophysiology. Int J Moles Sci. 2020; 21(3): 1075 .

27. Stefanini L, Bergmeier W. RAP GTPAses and platelet integrin signaling. Platelets. 2019;30(1):41-47.

28. Desai A, Bergmeier W, Canault M, et al. Phenotype analysis and clinical managemont in a large family with a novel truncating mutation in RASGRP2, the CalDAGGEFI encoding gene. Res Tract Thromb Haemost. 2017;1(1):128-133.

29. Rognoni E, Ruppert R, Fassler R. The kindlin family: functions, signaling properties and implications in disease. J Cell Sci. 2016;129 (1):17-27.

30. Junk K, Schulz AS, Kehrel BE, et al. Novelintegrin dependent platelet malfunction in siblings with leukocyte adhesion deficiencyIII (LAD-III) caused by a point mutation in FERMT3. Thromb Haemost 2010;103(5): 1053-1054.

31. Nagy M, Mastenbroek TG, Mattheij NJA, et al. Variable impairment of platelet functions in patients with severe genetically linked immune deficiencies. Haematological. 2018;103(3):540-549.

32. Moser M, Nieswandt B, Isar S, Pozgajova $M$, Fassler R. Kindlin-3 is an essential cofactor for integrin activation and platelet aggiegation. Nat Med. 2008;14(3):325-330.

33. Kuijpers T.W, van de Vijver E, Weterman $M A$ et al. LAD-1/variant syndrome is caused by mutations in FERMT3. Blood. 2009;113(19):4740-4746.

34. Kalinin NL, Plow EF, Byzova TV. Kindling in FERM adhesion. Blood. 2010;115(20):40114017.

35. Weiss HJ. Scott syndrome: a disorder of platelet coagulant activity. Serin Hematol. 1994;31(4):312-319.

36. Suzuki J, Umeda M, Sims PJ, Nagata S. Calcium-dependent phospholipid scrambling by TMEM16F. Nature. 2010;458(7325): 834-838.

37. Tot F, Salta N, Fressinaud E, Meyer D, Freyssinet JM. Scott syndrome characterized by impaired transmembrane migration of procoagulant phosphatidylserine and hemorrhagic complications, is an inherited disorder. Blood. 1996;87(4):1409-1415.

38. Lhermusier T, Chap H, Payrastre B. Platelet membrane phospholipid asymmetry: from the characterization of a scramblase activity to the identification of an essential protein mutated in Scott syndrome. J Thromb Haemost. 2011;9(10):1883-1891.

39. Millington-Burgess SL, Harper MT. Gene of the issue: ANO6 and Scott syndrome. Platelets. 2020;31(7):964-967

40. Reedy EC, Rand ML. Procoagulant posphatidylserine-exposing platelets in vito and in vino. Front Cardiovasc Med. 2020;7:15.

41. Boisseau P, Bee MC, Besnard T, et al. A new mutation of ANO6 in two familial cases of Scott syndrome. Br J Haematol. 2018;180(5):750-752.

42. Castoldi E, Collins PW, Williamson PL, Revers EM. Compound heterozygosity for 2 novel TMEM16F mutations in a patient with Scott syndrome. Blood. 2011;117(16): 4399-4400.

43. Berrou E, Soukaseum C, Favier R, et al. A mutation of the human EPHB2 gene leads to a major platelet functional defect. Blood. 2018;132(19):2067-2077.

44. Cattaneo M. The platelet P2Y12 receptor for adenosine diphosphate: congenital and drug-induced defects. Blood. 2011;117(7): 2102-2012.

45. Cattaneo M, Lecchi A, Randi AM, McGregor JL, Mannucci PM. Identification of a new congenital detect of platelet functin characterized by severe impairment of platelet responses to adenosine diphosphate. Blood. 1992;80(11):2787-2796.

46. Nurden P, Sari P, Heilmann E, et al. An inherited bleeding disorder linked to a defective interaction between $\mathrm{ADP}$ and its receptor on platelets. Its influence on glycoprotein lIbIII complex function. J Chin Invest. 1995;95(4):1612-1622.

47. Mundell SJ, Rabbolini D, Gabrielle S, et al. Receptor homodimerization plays a critical role in a novel dominant negative P2RY12 variant identified in a family with severe bleeding. J Thromb Haemost. 2018;16(1):4453.

48. Lecchi A, Feria EA, Paoletta S, et al. Inherited dysfunctional platelet P2Y12 receptor mutations associated with bleeding disorders. Hamostaseologie. 2016;36(4):279283.

49. Cattaneo M, Zighetti ML, Lombardi R, et al. Molecular bases of defective signal transductimon in the platelet P2Y12 receptor of a patient with congenital bleeding. Proc Natl Aced Sci U S A. 2003;100(4):1978-1983.

50. Chang K, Zhang J, Gao ZG, et al. Structure of the human P2Y12 receptor in complex with an antithrombotic drug. Nature. 2014;509(7498):115-118.

51. Nisan S, Daly ME, Federici AB, et al. An intact PDZ motif is essential for correct P2Y12 purinoceptor traffic in human platelets. Blood. 2011;118(20):5641-5651.

52. Patel YM, Lordkipanidze M, Lowe GC, et al. A novel mutation in the P2Y12 receptor and a function-reducing polymorphism in protease-activated receptor 1 in a patient with chronic bleeding. J Thromb Haemost. 2014;12(5):716-725.

53. Daly ME, Dawood BB, Lester WA, et al. Identification and characterization of a novel P2Y12 variant in a patient diagnosed with type I van Willebrand disease in the European MCMDM-1VWD study Blood. 2009;113(17):4110-4113.

54. Mammadova-Bach E, Olivier V, Loyau S, et al. Platelet glycoprotein VI binds to polymerized fibrin and promotes thrombin generaion. Blood. 2015;1260:683-691.

55. Reyes J, Watson SP, Nieswandt B. Functional significance of the platelet immune receptors CLEC-2 and GPVI. J Chin Invest. 2019;129(1):12-23.

56. Moro M, Jung SM, Okuma M, Shinmyozu K. A patient with platelets deficient in glycoprotein VI that lack both collagen-induced aggregation and adhesion. J Chin Invest. 1989;84(5):1440-1445.

57. Nurden AT. Clinical significance of altered platelet collagen-receptor functioning in platelets with emphasis on glycoprotein VI. Blood Rev. 2019:38:100592.

58. Jandrot-Perrus M, Herman C, Mezzano D. Platelet glycoprotein VI genetic quantitative and qualitative defects. Platelets. 2019;30(6):708-713.

59. Matus V, Valenzuela G, Baez CG, et al. An adenine insertion in exon 6 of human GP 6 generates a truncated protein associated with a bleeding disorder in four Chilean families. J Thromb Haemost. 2013;11(9): 1751-1759.

60. Nisan SP, Jones ML, Cunningham MR, Mumford $\mathrm{AD}$, Mundell SJ, on behalf of the UK GAPP study group. Rare platelet GPCR variants: what can we learn? Br J Pharmacol. 2015;172(13):3242-3253.

61. Habit, A, FitzGerald, GA, Maclouf, J. Phosphorylation of the thromboxane receptor alpha, the predominant isoform expressed in human platelets. J Biol Chem. 1999;274(5):2645-265.

62. Hirata T, Kakizuka A, Ushikubi F, Fuse I, Okuma M, Narumiya S. Arg60 to Leu mutatimon of the human thromboxane $\mathrm{A} 2$ receptor in a dominantly inherited bleeding disorder J Chin Invest. 1994;94(4):1662-1667.

63. Fuse I, Hattori A, Mito M, et al. Pathogenetic analysis of five cases with a platelet disorder characterized by the absence of thromboxane A2 (TXA2)-induced platelet aggregation in spite of normal TXA2 binding activity. Thromb Haemost. 1996;76(6):1080-1085.

64. Mundell SJ, Mumford A. TBXA2R gene variants associated with bleeding. Platelets. 2018;29(7):739-742.

65. Lebozec K, Jandrot-Perrus M, Avenard G, Favre-Bulle O, Billiard P. Design, developmont and characterization of ACT017, a humanized Fab that blocks platelet's glycoprotein VI function without causing bleeding risks. MAds. 2017;9(6):945-958.

66. Mammadova-Bach E, Gil-Pulido J, Sarukhanyan E, et al. Platelet glycoprotein VI promotes metastasis through interaction with cancer cell-derived galectin-3. Blood. 2020;135(14):1146-1160.

67. Huizing M, Helip-Wooley A, Westbrook W, Gunay-Aygun M, Gahl WA. Disorders of lysosome-related organelle biogenesis: clinecal and molecular genetics. Ann Rev Genomics Hum Genet. 2008;9:359-386.

68. Bowman SL, Bi-Karchin J, Le L, Marks MS. The road to lysosome-related organelles: insights from Hermansky-Pudlak syndrome and other rare diseases. Traffic. 2019;20(6): 404-435.

69. Ambrosio AL, Di Pietro SM. Storage pool diseases illuminate platelet dense granule biogenesis. Platelets. 2017;28(2):138-146.

70. Huizing M, Malicdan MCV, Wang JA, et al. Hermansky-Pudlak syndrome: mutation update. Hum Mutate. 2020;42(3):543-580.

71. Karampini E, Bierings R, Voorberg J. Orchestration of primary hemostasis by platelet and endothelial lysosome-related organelles. Arterioscler Thromb Vase Biol. 2020;40(6):1441-1453.

72. Enders A, Zieger B, Schwartz K, et al Lethal hemophagocytic lymphohistiocytosis in 
Hermansky-Pudlak syndrome type II. Blood. 2006;108(1):81-87.

73. Sharda A, Kim SH, Jasuja R, et al. Defective PDI release from platelets and endothelial cells impairs thrombus formation in Hermansky-Pudlak syndrome. Blood. 2015;125(10):1633-1642.

74. Kaplan J, De Domenico I, McVey Ward D. Chediak-Higashi syndrome. Curr Opin Hematol. 2008;15(1):22-29.

75. Dawood BB, Lowe GC, Lordkipanidze M, et al. Evaluation of participants with suspected heritable platelet function disorders including recommendation and validation of a streamlined agonist panel. Blood. 2012:120(5):5041-5049.

76. Rabbolini D, Connor D, Morel-Kopp MC, et al. An integrated approach to inherited platelet disorders: results from a research collaborative, the Sydney Platelet Group. Pathology. 2020;52(2):243-255.

77. Leo VC, Morgan NV, Bem D, et al. Use of next-generation sequencing and candidate gene analysis to identify underlying defects in patients with inherited platelet function disorders. J Thromb Haemost. 2015;13(4): 643-650.

78. Gorski MM, Lecchi A, Femia EA, et al. Complications of whole-exome sequencing for causal gene discovery in primary platelet secretion defects. Haematologica. 2019;104 (10):2084-2090

79. Sandrock K, Nakamura L, Vraetz T, Beutel $\mathrm{K}$, Ehl S, Zieger B. Platelet secretion defect in patients with familial hemophagocytic lymphohistiocytosis type 5 (FLH5). Blood. 2010;116(26):6148-6150

80. Ye S, Karim ZA, Al Hawas R, Pessin JE, Filipovich AH, Whiteheart SW. Syntaxin-11 but not syntaxin-2 or syntaxin-4, is required for platelet secretion. Blood. 2012;120(12): 2484-2492.

81. Nakamura L, Bertling A, Brodde MF, et al.
First characterization of platelet secretion defect in patients with familial hemophagocytic lymphohistiocytosis type 3 (FHL-3). Blood. 2015;125(2):412-414

82. Fager Ferrari MF, Leinoe E, Rossing M, et al. Germline heterozygous variants in genes associated with familial hemophagocytic lymphohistiocytosis as a cause of increased bleeding. Platelets. 2017;29(1):56-64.

83. Rao AK. Inherited defects in platelet signaling mechanisms. J Thromb Haemost. 2003;1(4):671-681.

84. Adler DH, Cogan JD, Phillips JA III, et al. Inherited human cPLA2 deficiency is associated with impaired eicosanoid biosynthesis, small intestinal ulceration, and platelet dysfunction. J Clin Invest. 2008;118(6):21212131.

85. Faioni EM, Razzari C, Zuleta A, et al Bleeding diathesis and gastro-duodenal ulcers in inherited cytosolic phospholipaseA2 alpha deficiency. Thromb Haemost. 2014;112(6):1182-1189.

86. Reed K, Tucker DE, Aloulou A, et al Functional characterization of mutations in inherited human CPLA2 deficiency. Biochemistry. 2011;50(10):1731-1738.

87. Rolf N, Knoefler R, Bugert P, et al. Clinical and laboratory phenotypes associated with the aspirin-like defect: a study in 17 unrelated families. Br J Haematol. 2009;144(3):416424.

88. Bastida JM, Lozano ML, Benito R, et al Introducing high-throughput sequencing into mainstream genetic diagnosis practice in inherited platelet disorders. Haematologica. 2018;103(1):148-162.

89. Chan MV, Hayman MA, Sivapalaratnam S, et al. Identification of a homozygous recessive variant in PTGS1 resulting in a congenital aspirin-like defect in platelet function. Haematologica. 2020 April 16. [Epub ahead of print]
90. Geneviève $\mathrm{D}$, Proulle $\mathrm{V}$, Isidor $\mathrm{B}$, et al Thromboxane synthase mutations in an increased bone density disorder (Ghosal syndrome). Nat Genet. 2008;40(3):284-286.

91. Seligsohn U. Treatment of inherited platelet disorders. Haemophilia. 2012;18 (Suppl 4:)161-165.

92. Civaschi E, Klersy C, Melazzini F, et al. Analysis of 65 pregnacies in 24 women with five different forms of platelet function disorders. Br J Haematol. 2015;170(4):559-563.

93. Lambert MP. Inherited platelet disorders: A modern approach to evaluation and treatment. Hematol Oncol Clin North Am. 2019;33(3):471-487.

94. Freson K, Turro E. High-throughput sequencing approaches for diagnosing hereditary bleeding and platelet disorders. J Thromb Haemost. 2017:15(7):1262-1272.

95. Thaventhiran JED, Lango Allen H, Burren OS et al. Whole-genome sequencing of a sporadic primary immunodeficiency cohort. Nature. 2020;583(7814);90-95.

96. Westbury SK, Turro E, Greene D, et al Human Phenotype Ontology annotation and cluster analysis to unravel genetic defects in 707 cases with unexplained bleeding and platelet disorders. Genome Med. 2015;7(1):36.

97. Greinacher A, Pecci A, Kunishima S, et al. Diagnosis of inherited platelet disorders on a blood smear: a tool to facilitate worldwide diagnosis of platelet disorders. J Thromb Haemost. 2017;15(7):1511-1521.

98. Greinacher A, Eekels JJM. Simplifying the diagnosis of inherited platelet disorders? The new tools do not make it easier. Blood. 2019;133(23):2478-2483.

99. Rodeghiero F, Pabinger I, Ragni M, et al. Fundamentals for a systematic approach to mild and inherited bleeding disorders: An EHA concensus report. Hemasphere. 2019;3 (5):e286. 